\title{
AC 2008-532: USING FAILURE CASE STUDIES TO ADDRESS CIVIL ENGINEERING PROGRAM AND BOK CRITERIA
}

Norb Delatte, Cleveland State University 


\title{
Using Failure Case Studies to Address Civil Engineering Program and BOK Criteria
}

\begin{abstract}
This paper suggests ways that failure case studies may be used to address Accreditation Board for Engineering and Technology Engineering Accreditation Commission (ABET EAC) general and civil engineering program specific criteria, as well as Civil Engineering Body of Knowledge (BOK) criteria. The study of engineering failures can offer students valuable insights into associated technical, ethical, and professional issues. Lessons learned from failures have substantially affected civil engineering practice. The history of development of practice in many engineering disciplines is, in large part, the story of failures and of the changes to standards and procedures made as the result of forensic analyses. In addition to technical issues, concepts such as professional and ethical responsibility are highlighted by the cases. Some specific examples are presented.
\end{abstract}

\section{Introduction}

The requirements that civil engineering programs have to meet now, and will have to meet in the future, are contained in a number of documents. These include the general and program specific Accreditation Board for Engineering and Technology Engineering Accreditation Commission (ABET EAC) criteria $^{1}$ and the Civil Engineering Body of Knowledge $(\mathrm{BOK})^{2}$. ASCE also publishes a commentary on the ABET EAC criteria ${ }^{3}$.

The Civil Engineering Body of Knowledge (BOK) has been developed by ASCE over several years, and is expected to affect ABET EAC accreditation criteria at the bachelor's and master's level for civil engineering programs. Some of the BOK outcomes will present challenges for faculty and programs. It will be necessary to develop new educational materials and teaching techniques to facilitate BOK implementation.

As an example, BOK outcomes 13 - 15 require graduates to explain concepts and problem solving processes involving management, business, public policy, public administration, and leadership. These topics may not be addressed in current or future courses. Instead, it may be preferable to integrate the topics into existing courses.

These outcomes can be difficult to document, unless case studies are included in the curriculum. None of these documents specifically mentions failure case studies. This paper argues that they are one of the methods that may be used to address these outcomes.

In February 2008, ASCE published the second edition of the BOK ${ }^{4}$. These 24 outcomes are different from the 15 in the original BOK, although the report provides tables to show how the old outcomes map to the new. 


\section{General Program Criterion 3 - Program Outcomes}

ABET EAC criterion 3 defines 11 program outcomes that all engineering programs must meet and document, not just civil engineering programs.

"Engineering programs must demonstrate that their students attain the following outcomes:

(a) an ability to apply knowledge of mathematics, science, and engineering

(b) an ability to design and conduct experiments, as well as to analyze and interpret data

(c) an ability to design a system, component, or process to meet desired needs within realistic constraints such as economic, environmental, social, political, ethical, health and safety, manufacturability, and sustainability

(d) an ability to function on multidisciplinary teams

(e) an ability to identify, formulate, and solve engineering problems

(f) an understanding of professional and ethical responsibility

(g) an ability to communicate effectively

(h) the broad education necessary to understand the impact of engineering solutions in a global, economic, environmental, and societal context

(i) a recognition of the need for, and an ability to engage in life-long learning

(j) a knowledge of contemporary issues

(k) an ability to use the techniques, skills, and modern engineering tools necessary for engineering practice."

ABET requires that these 11 outcomes be met as part of the undergraduate program. It is a relatively straightforward process to document the technically oriented outcomes. However, it is a little more difficult to address some of the softer or less technical outcomes (referred to at least once at the ASEE 2007 annual meeting as the "squishier outcomes") such as c, f, h, and i.

Programs often struggle with how to document that their graduates understand the impact of engineering solutions in a global and societal context, engage in life-long learning, and demonstrate knowledge of contemporary issues (criteria $\mathrm{h}, \mathrm{i}$, and $\mathrm{j}$, respectively). These outcomes can be difficult to demonstrate. One method of documenting these particular outcomes is to include case studies of failed engineering works in the curriculum. Many case studies show the direct societal impact of failures, and demonstrate the need for life-long learning by highlighting the evolutionary nature of engineering design procedures.

Case studies also address the revised outcome c, design within realistic constraints. Case studies, and specifically failure case studies, illuminate how "economic, environmental, social, political, ethical, health and safety, manufacturability, and sustainability" impact design, behavior, and performance of engineered systems.

Case studies of recent failures may be used to support outcome $\mathrm{j}$, knowledge of contemporary issues. As students encounter contemporary failure case studies, they may realize the limits of their technical knowledge and become inspired to research advanced topics on their own, thus further facilitating outcome i, lifelong learning. 


\section{Illustrative Case Study - The Quebec Bridge Collapse of 1907}

The 1907 collapse of the Quebec Bridge during construction represents a landmark of both engineering practice and forensic engineering ${ }^{5}$. The Quebec Bridge was the longest cantilever structure attempted until that time. In its final design, it was 1,800 ft long. The bridge project was financially troubled from the beginning. This caused many setbacks in the design and construction.

Construction began in October 1900. Figure 1 shows the state of construction just before the collapse. In August 1907, the bridge collapsed suddenly. Seventy-five workers were killed in the accident, and there were only eleven survivors from the eighty-six workers on the span. The wreckage is shown in Figure 2.

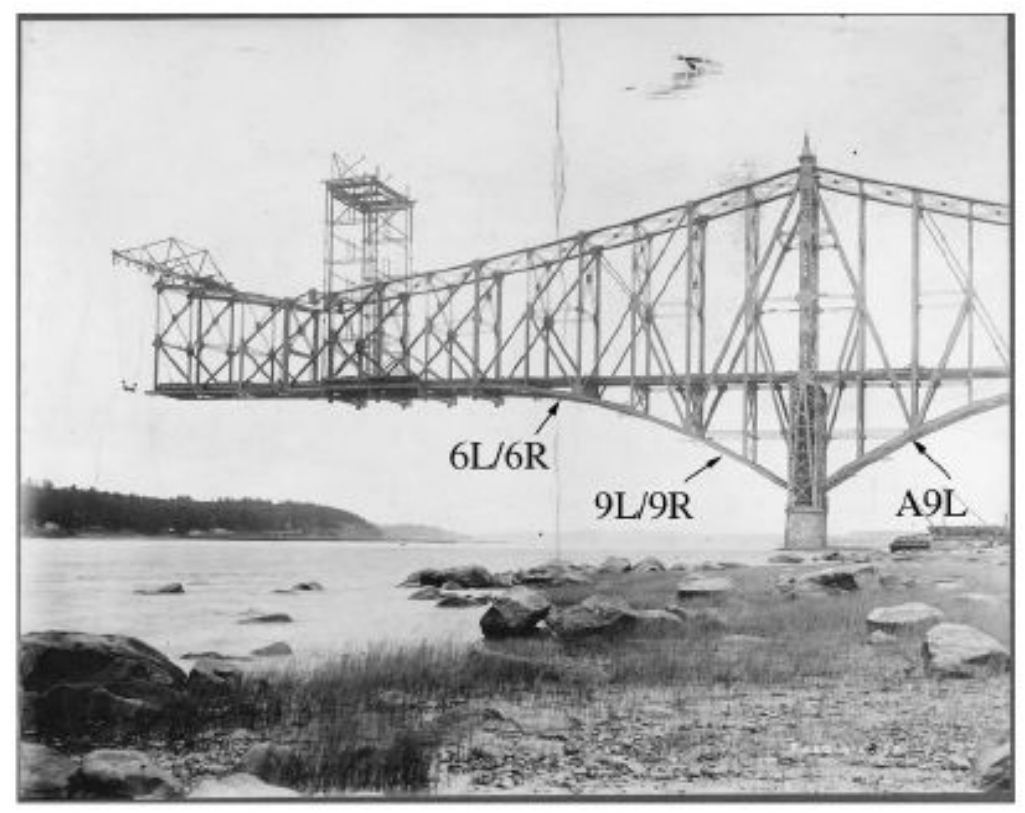

Figure 1: The Quebec Bridge just before the collapse, photo courtesy Archives Canada

A distinguished panel was assembled to investigate the disaster. The panel's report found that the main cause of the bridge's failure was improper design of the latticing on the compression chords. The collapse was initiated by the buckling failure of Chord A9L, immediately followed by Chord A9R. These were the anchor arm lower compression chords, at the base of the truss near the pier, as shown in Figure 1.

Theodore Cooper had been the consulting engineer for the Quebec Bridge project, and most of the blame for the disaster fell on his shoulders. He mandated unusually high allowable stresses, and failed to require recalculation of the bridge dead load when the span was lengthened. 


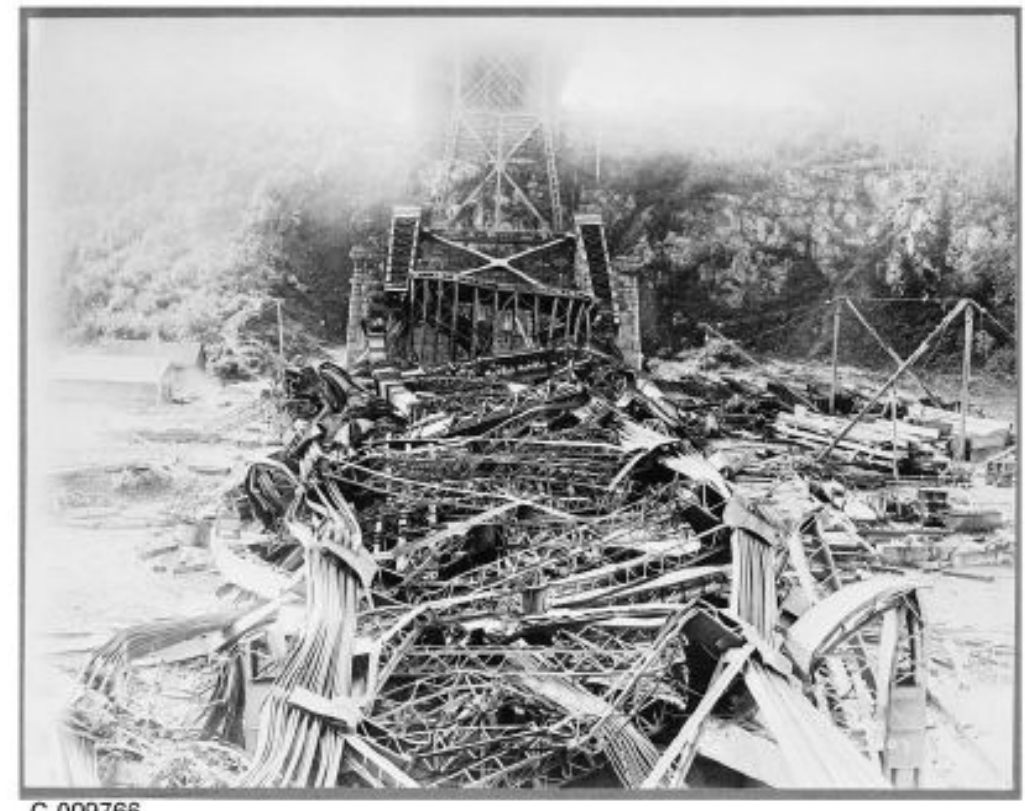

C-009766

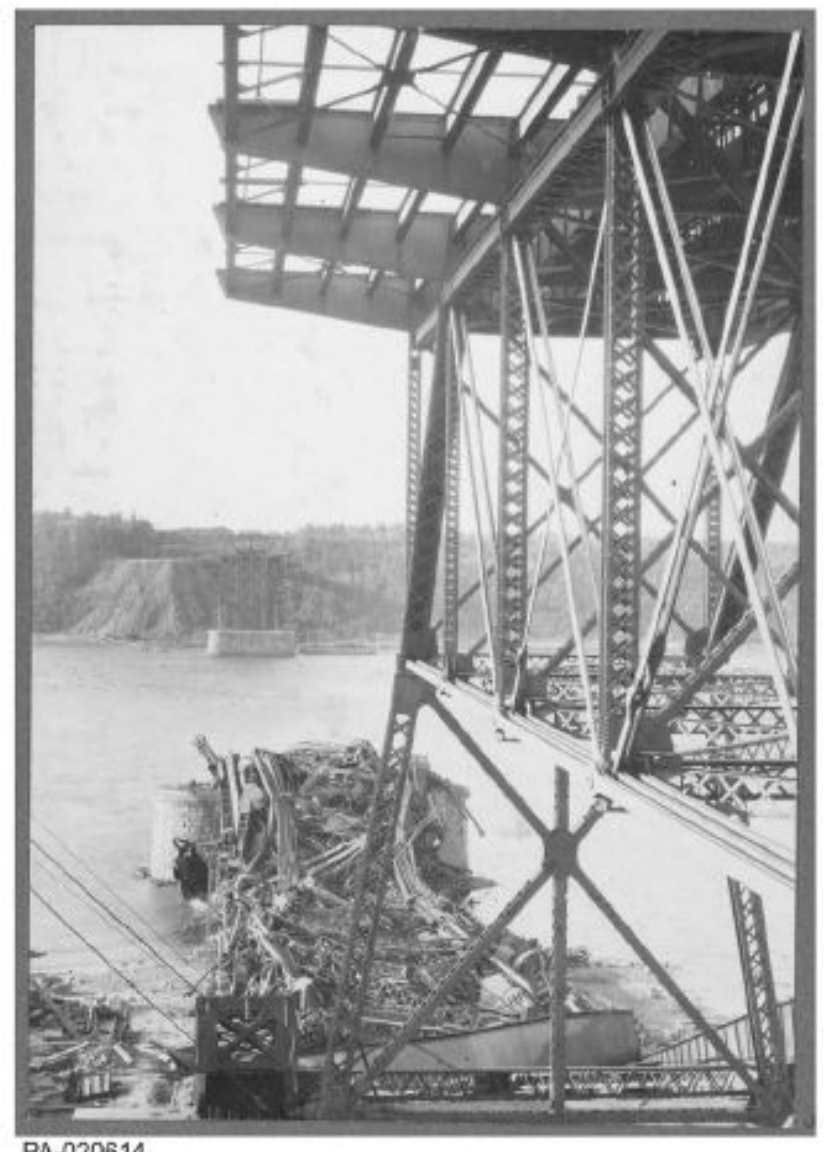

Figure 2: The collapsed Quebec Bridge, photos courtesy Archives Canada

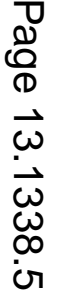


Mr. Cooper attempted to supervise the construction of a bridge in Quebec from his office in New York City. When problems arose, the problems were referred to him for a decision. The absence of an onsite engineer with authority to stop the work meant that there was no way to head off the impending collapse. A meeting was held to decide what to do, and the bridge collapsed just as the meeting was breaking up. The inability to make and implement a timely decision illustrates the importance of effective communication (outcome g). It has been argued that Cooper failed to fulfill his professional and ethical responsibilities (outcome $\mathrm{f})^{5}$.

Mr. Cooper planned for the Quebec Bridge to be the crowning achievement of an illustrious career as a bridge engineer. However, by this time his health was poor and he was unable to travel to the site. He was also poorly compensated for his work. Cooper's difficulties show some of the realistic constraints (outcome c) inherent in every engineering project.

Following the collapse, organizations such as ASCE began to define better the responsibility of the engineer of record. Unfortunately, the collapse of the Hyatt Regency Walkways three quarters of a century later showed that much remains to be done ${ }^{5}$.

\section{Civil Engineering Program Specific Criteria}

The CE program specific criteria include "apply knowledge of four technical areas appropriate to civil engineering;... explain basic concepts in management, business, public policy, and leadership; and explain the importance of professional licensure." ${ }^{1}$ In the faculty case study workshops, discussed later in this paper, failures from several technical areas appropriate to civil engineering are presented. These include structural, foundation and geotechnical failures, and dam failures.

ABET requires that the program-specific criteria be met as part of the undergraduate program. The ways that these can be met are outlined in more detail in the section below on the BOK. Case studies such as the Hyatt Regency collapse can reinforce the importance of professional licensure by illustrating the responsibilities of the Engineer of Record. ${ }^{7}$

\section{Civil Engineering Body of Knowledge - First Edition}

The first edition BOK has 15 outcomes, the first 11 of which are identical to the ABET a $-\mathrm{k}$, above. The other four are

"12. an ability to apply knowledge in a specialized area related to civil engineering. 13. an understanding of the elements of project management, construction, and asset management.

14. an understanding of business and public policy and administration fundamentals. 15. an understanding of the role of the leader and leadership principles and attitudes."2

The BOK outcomes may be met as part of the undergraduate program, in graduate study, in co-curricular or extracurricular activities, or during post-BS engineering experience before licensure. 
In many cases, understanding failures requires the ability to understand and apply technical concepts from a specialized area in civil engineering, such as structural or geotechnical engineering (outcome 12). In fact, many of the advances in specialized areas have been due to failures and the subsequent forensic investigations.

Failures may occur due to gaps or miscommunication in project management, construction, or asset management (outcome 13). This may include collapses due to lack of maintenance. The role that poor communication frequently plays is disheartening.

In the course of analyzing failure cases, issues of business, public policy, and administration may come into play (outcome 14). Project constraints, often financial, can lead to situations where safety margins are substantially reduced. Following the Quebec Bridge collapse, the government of Canada took over the project and completed it, and the inquiry faulted the business model that had been applied in the original construction.

The roles that individuals play in failures, such as Cooper at Quebec and Moisseiff at Tacoma Narrows, ${ }^{8}$ can illustrate the way leadership (or lack of it) can avert problems or make them worse (Outcome 15). LeMessurier's leadership in repairing his flawed Citicorp Tower has been upheld as a good example, although the opposite view has been put forward as well. ${ }^{9}{ }^{10}$

\section{Civil Engineering Body of Knowledge - Second Edition}

As noted above, the BOK second edition was published very recently (February 2008), and there are some very significant changes from the first edition. Some of the new outcomes that seem to be well supported by the use of failure case studies include:

"11: Contemporary issues and historical perspectives. Analyze the impact of historical and contemporary issues on the identification, formulation, and solution of engineering problems and analyze the impact of engineering solutions on the economy, environment, political landscape, and society.

12: Risk and uncertainty. Analyze the loading and capacity, and the effects of their respective uncertainties, for a well-defined design and illustrate the underlying probability of failure (or nonperformance) for a specified failure mode.

22: Attitudes. Demonstrate attitudes supportive of the professional practice of civil engineering."

Of course, many of the ABET and first edition BOK outcomes are carried over to the second edition of the BOK. The relationships are shown on pages 101 and 102 of the ASCE BOK2 report ${ }^{4}$.

\section{Role of Faculty Failure Case Study Workshops}

Over the years, the ASCE Technical Council on Forensic Engineering (TCFE) has carried out several surveys of civil engineer programs across the U.S. One common theme of the 
responses was that there was considerable interest in including failure case studies in courses, and that there was a lack of available materials suitable for classroom use ${ }^{11}$. As a result, considerable effort has been put by TCFE into developing case study materials suitable for classroom use.

For the past few years, the ASCE TCFE has offered faculty workshops on failure case studies in the curriculum, funded by NSF and ASCE. To date, five workshops have been offered in various locations (2003 - 2007), with about a hundred faculty participants in total. Details about the workshops were presented at the ASEE 2007 annual meeting. ${ }^{12}$

The ASCE TCFE workshops have focused on linking case studies to specific topics in one or more civil engineering or engineering mechanics courses. Case study presentations and reading assignments have been developed to build student knowledge, and these have been provided in the workshop materials.

The case studies may be used to introduce topics and stimulate classroom discussion. Students may be given specific homework examples and examination problems that require application of the case studies. These assignments can provide documentation that the specific outcomes have been met.

The workshop participants have been surveyed about how they are using case studies for pedagogical aims. Eighteen responses were received, and of those fourteen were using case studies some or a lot. All fourteen agreed that the benefits of using the case studies justified the necessary time and effort. Complete results are reported elsewhere ${ }^{14}$. The project is ongoing, and more results will be reported as they become available.

\section{Assessment}

Of course, what we think we are teaching does not matter nearly as much as what students learn. It is necessary to develop assessment methods and instruments to determine if the students are in fact meeting the outcomes cited above, and to document that they are. A multiyear project is underway entitled "Assessing the Impact of Case Studies on the Civil Engineering and Engineering Mechanics Curriculum."13 14 Results so far from student surveys and student focus groups indicate that the students believe that the case studies inspire them to learn, and help them understand the importance of non-technical issues in engineering practice. The materials developed under this project will be published as they become available.

Student learning has been assessed through surveys as well as focus groups, led by researchers from the Cleveland State University College of Education and Human Services. The case studies were pilot tested in the spring of 2007 in two courses, Strength of Materials (sophomore, engineering mechanics, ESC 211) and Construction Planning and Estimating (senior, civil engineering, CVE 403).

Student survey results showed considerable support of outcomes a, $\mathrm{f}$, and $\mathrm{j}$ from both sophomores and seniors, as well as $\mathrm{h}$ from sophomores and $\mathrm{d}, \mathrm{e}, \mathrm{j}$, and $\mathrm{k}$ from seniors. All of these outcomes were rated by students at 4 or higher on a 5 point scale, from 1 - strongly 
disagree to 5 - strongly agree. The students also reported that the incorporation of failure case studies contributed to their interest in and understanding of the course material. Complete results, including comments from the student focus groups, are reported elsewhere ${ }^{14}$. The project is ongoing, and more results will be reported as they become available.

\section{Summary and Conclusions}

Lessons learned from failures have substantially affected civil engineering practice. The history of development of practice in many engineering disciplines is, in large part, the story of failures and of the changes to standards and procedures made as the result of forensic analyses. In addition to technical issues, concepts such as professional and ethical responsibility are highlighted by the cases. Some specific examples are presented.

Some of the ways that failure case studies may be used to address specific general, program, and BOK criteria have been discussed in this paper. Some specific examples are provided, and others may be found elsewhere. ${ }^{12,13,14}$

The materials developed throughout this effort are being used to develop a book of failure case studies in the civil engineering and engineering mechanics curriculum that will be published by ASCE Press later this year. ${ }^{15}$

\section{Acknowledgement:}

This work was sponsored by the grant "Assessing the Impact of Case Studies on the Civil Engineering and Engineering Mechanics Curriculum," National Science Foundation Project DUE-0536666, \$ 125,000, July 1, 2006 - June 30, 2009, program officer Russell L. Pimmel. Opinions expressed are solely those of the authors and not of the National Science Foundation.

\section{Bibliographic Information}

${ }^{1}$ Accreditation Board for Engineering and Technology, Inc (ABET) (2007), Engineering Accreditation Commission, Criteria for Accrediting Engineering Programs, Effective for Evaluations During the 20082009 Accreditation Cycle, Baltimore, Maryland, December 4, 2007.

${ }^{2}$ American Society of Civil Engineers (2004), Civil Engineering Body of Knowledge for the $21^{\text {st }}$ Century, ASCE, Reston, Va.

${ }^{3}$ American Society of Civil Engineers (2007), Commentary On the ABET Engineering Criteria for Civil and Similarly Named Programs In the Context of the Civil Engineering Body of Knowledge, ASCE, Reston, Va.

${ }^{4}$ American Society of Civil Engineers (2008), Civil Engineering Body of Knowledge for the $21^{\text {st }}$ Century, Second Edition, ASCE, Reston, Va.

${ }^{5}$ Roddis, W. M. K. (1993). “Structural Failures and Engineering Ethics,” J. Struct. Engrg., ASCE, 119(5), 15391555.

${ }^{6}$ Pearson, Cynthia, and Norbert Delatte (2006), “The Collapse of the Quebec Bridge, 1907,” ASCE Journal of Performance of Constructed Facilities, February 2006

${ }^{7}$ Gillum, J. D. (2000) “The Engineer of Record and Design Responsibility," ASCE Journal of Performance of Constructed Facilities, May 2000.

${ }^{8}$ Petroski, H. Engineers of Dreams, 1995 
${ }^{9}$ Morganstern, J., (1997), “The Fifty-Nine-Story Crisis," Journal of Professional Issues in Engineering Education and Practice, ASCE, January 1997.

${ }^{10}$ Kremer, E. (2002) "(Re)examining the Citicorp Case: Ethical Paragon or Chimera," Cross Currents, Association for Religion and Intellectual Life, Vol. 52, No. 3, Fall 2002

${ }^{11}$ Delatte, N., and Rens, K., "Forensics and Case Studies in Civil Engineering Education: State-of-the-Art," ASCE Journal of Performance of Constructed Facilities, Vol. 16, No. 3, August, 2002.

${ }^{12}$ Delatte, N., Bosela, P., Rens, K., Carper, K., and Sutterer, K., Findings from Workshops on Failure Case Studies in the Civil Engineering and Engineering Mechanics Curriculum, 2007 ASEE Annual Meeting

${ }^{13}$ Delatte, N., Sutton, R., Beasley, W., and Bagaka's, J., Assessing the Impact of Failure Case Studies on the Civil Engineering and Engineering Mechanics Curriculum, 2007 ASEE Annual Meeting

${ }^{14}$ Delatte, N., Bosela, P., Sutton, R., Beasley, W., and Bagaka's, J., Assessing the Impact of Case Studies on the Civil Engineering and Engineering Mechanics Curriculum, Phase II, 2008 ASEE Annual Meeting

${ }^{15}$ Delatte, N., Beyond Failure: Forensic Case Studies for Civil Engineers, ASCE Press, 2008 